\title{
Medicine shortages in Australia - what are we doing about them?
}

\begin{abstract}
Steve Morris
Executive director,

SA Pharmacy

Chief pharmacist, SA Health

Department of Health and Wellness, Government of SA

Adelaide
\end{abstract}

\section{Keywords}

drug industry, drug regulation, medicine shortages, Therapeutic Goods Administration

Aust Prescr 2018;41:136-7 https://doi.org/10.18773/ austprescr.2018.047
The first objective of the Australian National Medicines Policy is to provide 'timely access to the medicines that Australians need, at a cost individuals and the community can afford'. However, even developed countries such as Australia can experience shortages of medicines. These can lead to patient harm due to a result of non-treatment, undertreatment, the use of less appropriate alternatives and medicines safety issues. ${ }^{2,3}$ Addressing these shortages consumes significant clinical effort and there are financial and logistical impacts on healthcare systems and all stakeholders. ${ }^{3}$

In a 2017 survey of Australian hospitals the five most common medicines in short supply were antibiotics, anaesthetics, cardiology drugs, endocrinology drugs and chemotherapy. Such shortages can have a significant impact on patient care with little or no notice. ${ }^{2}$ In 2018 there was a shortage of the EpiPen device for emergency self-administration of adrenaline (epinephrine). Vaccines and even water for injections have been in short supply.

Medicine shortages are not a new problem but the extent and scope has worsened over recent years. ${ }^{4}$ The causes of medicine shortages could be described as a spider's web of diverse interacting and connected factors including regulation, manufacturing, procurement, global acquisitions, financial viability, political instability and even natural disasters. ${ }^{2,3}$ Medicine shortages are inherently an international issue. However, as Australia accounts for only $2 \%$ of the global market and imports over $90 \%$ of its medicines, it is potentially more vulnerable than bigger markets which may be prioritised by suppliers in periods of shortage. ${ }^{4,5}$ Although international efforts should continue to focus on increasing the resilience of the global pharmaceutical supply chain, we have to consider how the potential consequences for Australian patients can be minimised.

In 2014, recognising the problems relating to medicine shortages, the Therapeutic Goods Administration (TGA) established the Medicines Shortage Information Initiative (MSII). ${ }^{6}$ This was an attempt to provide information and clarity to prescribers and pharmacists via a voluntary sponsor reporting scheme. ${ }^{6}$ However, this initiative has had major failings with some critical shortages not being reported. Also, few clinicians were aware of the initiative. ${ }^{4,5}$ This has led to instances in which a prescriber only becomes aware of a shortage after prescribing when they are informed by a community pharmacist or when hospitals receive notification from a wholesaler after placing an order. ${ }^{2,5}$

The current system leads to duplication of effort, inconsistency and creates a vicious cycle of local stockpiling leading to shortages of therapeutic alternatives within the wider health system and potential inequity of access to critical drugs across Australia. 2,4 The lack of inclusive, robust and timely information prevents effective system-wide strategies from being put in place. Effective strategies should discourage local stockpiling and minimise the impact on patients and the health system.

The strategies adopted to date have focused on anticipating, identifying and managing shortages. ${ }^{2,5}$ Strategies to extend existing supplies have included minimising waste and prioritising patient need in addition to providing a different formulation or a therapeutic alternative. This is in some respects a form of local rationing. The TGA can approve the temporary supply of a substitute medicine during a medicine shortage, and temporary listing of unregistered medicines on the Pharmaceutical Benefits Scheme (PBS) can be facilitated. However, this may not cover all medicine shortages and an alternative drug without PBS listing has obvious financial impacts on patients.

In response to these problems, in 2017 the Australian Health Minister called for the development of a strategy to support better management of shortages. The TGA has consulted on some proposals. ${ }^{4}$ These proposals are in line with the principles of transparency, coordination and communication between stakeholders articulated by the World Health Organization. ${ }^{7}$ One fundamental component of the proposals is that drug companies will be mandated to report shortages and the reporting will be made public for those drugs with the potential for extreme impacts on patients. Systematic, timely and transparent reporting is the foundation of a patient-centred approach to medicine shortages. Without this reporting, securing alternative drugs from overseas or rationing and prioritising the use of available medicines will not be possible. The proposals include a process for centralised systematic assessment and management of shortages including the establishment and maintenance of a medicine watchlist. Supply problems would be escalated 
to a National Medicines Action Group to provide advice on possible rationing or alternative therapies when needed. It is intended that comprehensive communication strategies will be evolved to inform all stakeholders about shortages and solutions.

The Australian Health Minister introduced the Therapeutic Goods Amendment (2018 Measures No. 1) Bill 2018 into the House of Representatives on 28 June $2018 .{ }^{8}$ The Bill encapsulates the core of the proposals in legislation and will come into effect on 1 January 2019. Successful implementation will require all stakeholders to embrace the principles of transparency, coordination and communication. Health professionals will need to understand the systems in place to address shortages and how they can stay informed.

The TGA website will be a critical primary source of information supplemented by health professional organisations and local mechanisms. The provision of information to aid both the prescribing of alternative drugs and the advice given to patients on the impact of a therapeutic change needs to be practical, understandable and timely.
In addition to national processes facilitated by the TGA, local health systems including hospitals will need to develop fair, legitimate and effective strategies for managing shortages and communicating effectively. This should include adopting practice standards such as those developed in Scotland. ${ }^{9}$ Robust governance mechanisms should be in place clarifying accountabilities and providing an ethical framework for decision making. ${ }^{10}$ Any proposed therapeutic alternatives need to be both accessible and affordable for patients.

Medicine shortages will continue to impact on patient care for the foreseeable future. It is simplistic to believe that there are straightforward solutions. However, the proposals outlined by the TGA, and now adopted in legislation, provide an important road map in moving towards a genuine patient-centred approach to medicine shortages in Australia to minimise potential harm. $<$

Steve Morris became Chief Executive Officer of NPS MedicineWise in September 2018.

\section{REFERENCES}

1. Department of Health and Ageing. National Medicines Policy 2000. Canberra: Commonwealth of Australia; 1999. http://www.health.gov.au/internet/main/publishing.nsf/ Content/national-medicines-policy [cited 2018 Sep 1]

2. Medicine shortages in Australia: a snapshot of shortages in Australian hospitals. Melbourne: The Society of Hospital Pharmacists Australia; 2017. https://www.shpa.org.au/ news/medicines-survey-reveals-hospitals-shortshelvedpharmacists-dark [cited 2018 Sep 1]

3. Why drug shortages occur. Drug Ther Bull 2015;53:33-6. https://doi.org/10.1136/dtb.2015.3.0316

4. Therapeutic Goods Administration. Management and communication of medicines shortages - proposed implementation approach. Consultation paper. Version 1.0, March 2018. www.tga.gov.au/consultation/consultationmanagement-and-communication-medicines-shortages [cited 2018 Sep 1]

5. Tan YX, Moles RJ, Chaar BB. Medicine shortages in Australia: causes, impact and management strategies in the community setting. Int J Clin Pharm 2016;38:1133-41. https://doi.org/10.1007/s11096-016-0342-1
6. Therapeutic Goods Administration. Medicine Shortages Information Initiative. 2018 Apr 27. www.tga.gov.au/ medicine-shortages-information-initiative [cited 2018 Sep 1]

7. Medicines shortages: global approaches to addressing shortages of essential medicines in health systems. WHO Drug Inf 2016;30:180-5. http://apps.who.int/medicinedocs/ en/m/abstract/Js22463en [cited 2018 Sep 1]

8. Therapeutic Goods Amendment (2018 Measures No.1) Bill 2018. www.aph.gov.au/Parliamentary_Business/ Bills_Legislation/Bills_Search_Results/Result?bld=r6143 [cited 2018 Sep 1]

9. NHS Scotland and Royal Pharmaceutical Society. Best practice standards for managing medicines shortages in secondary care in Scotland. London: Royal Pharmaceutical Society; 2017. www.rpharms.com/news/details/Standards for-the-management-of-medicines-shortages-in-secondarycare-launched [cited 2018 Sep 1]

10. Lipworth W, Kerridge I. Why drug shortages are an ethical issue. Australas Med J 2013;6:556-9. https://doi.org/10.4066/ AMJ.2013.1869 